\title{
Guarding the Green: Pathways to Stomatal Immunity
}

\author{
Katja Sawinski, ${ }^{1}$ Sophia Mersmann,, ${ }^{2}$ Silke Robatzek, ${ }^{2}$ and Maik Böhmer ${ }^{1}$ \\ ${ }^{1}$ Institut für Biologie und Biotechnologie der Pflanzen, Westfälische Wilhelms Universität, Schlossplatz 4, 48149 Münster, \\ Germany; ${ }^{2}$ The Sainsbury Laboratory, Norwich Research Park, Norwich, NR4 7UH, U.K.
}

Submitted 14 December 2012. Accepted 17 February 2013.

Guard cells regulate plant gas exchange and transpiration by modulation of stomatal aperture upon integrating external cues like photosynthetic effective illumination, $\mathrm{CO}_{2}$ levels and water availability and internal signals like abscisic acid (ABA). Being pores, stomata constitute a natural entry site for potentially harmful microbes. To prevent microbial invasion, stomata close upon perception of microbe-associated molecular patterns (MAMPs), and this represents an important layer of active immunity at the preinvasive level. The signaling pathways leading to stomatal closure triggered by biotic and abiotic stresses employ several common components, such as reactive oxygen species, calcium, kinases, and hormones, suggesting considerable intersection between MAMP- and ABA-induced stomatal closures, which we will discuss in this review.

A significant number of microbes-bacteria, oomycetes, and fungi- of the phyllosphere habitat use stomata to invade plant tissues. For example, uredospore and basidiospore germlings of the obligate biotrophic rust fungi have long been described to target stomatal pores as plant entry sites (Mendgen et al. 2006; Moldenhauer et al. 2006; Staples 2000), by which the germ tube specifically recognizes physical features of the outer ledge of stomatal pores (Dickinson 1949; Maheshwari et al. 1967). Likewise, germ tubes from zoospores of the oomycete Plasmopara viticola grow towards open stomata and penetrate into the substomatal space, where they form an infection structure (Espino and Nesbitt 1982; Kiefer et al. 2002). For completion of its life cycle, $P$. viticola also coopts stomata, and sporangiophores emerge through the stomatal pores four to five days after infection. Bacterial pathogens rely on natural openings and wound sites to gain access to plant tissues, and stomatal pores provide a major entry route into leaves (Hugouvieux et al. 1998). Pseudomonas syringae pv. tomato DC3000 selectively moves towards and enters open stomata on Arabidopsis thaliana leaves (Melotto et al. 2006). Confocal microscopy demonstrated distinct clustering of green fluorescent protein-tagged Salmonella enterica serovar Typhimurium within the guard cell pore complex of lettuce leaves, in particular the substomatal space and the apoplast of the spongy parenchyma (Kroupitski et al. 2009, 2011). Salmonella bacteria were able to penetrate stomata only in light, which is

K. Sawinski and S. Mersmann contributed equally.

Corresponding authors: S. Robatzke; E-mail: robatzek@TSL.ac.uk or M. Böhmer; E-mail: m.boehmer@uni-muenster.de

(C) 2013 The American Phytopathological Society caused by chemo-attraction through photosynthetic sugars (Kroupitski et al. 2009). Dark-induced stomatal closure prior to infection abolished Salmonella penetration, and bacteria were confined to the leaf surface.

Similarly, stomatal closure induced by dark-incubation or by abscisic acid (ABA) decreased the disease incidence and severity of Lycopersicon spp.-infected with Xanthomonas campestris pv. vesicatoria (Ramos and Volin 1987). In comparative experiments in which plants were syringe-infiltrated neither dark-incubation nor agents triggering stomatal closure showed any significant difference in susceptibility. Leaf-inoculation with $P$. syringae pv. tomato DC3000 or Escherichia coli O157:H7 decreased stomatal aperture within 1 to $2 \mathrm{~h}$ after inoculation (Melotto et al. 2006). P. syringae pv. tomato DC3000-inoculated plants, however, reopened their stomata after $3 \mathrm{~h}$ (Melotto et al. 2006). Taken together, these findings reinforce the importance of the guard cell pore complex as an active layer of plant immunity at the preinvasive level. The data further indicate that plant pathogens have developed mechanisms to prevent stomatal closure. In this review, we discuss current knowledge of microbe-induced stomatal closure and the overlap with abiotic stress signaling pathways regulating stomatal apertures.

MAMPs trigger the closure of stomata.

Plants recognize potentially harmful microbes by the perception of so-called microbe or pathogen-associated molecular patterns (MAMPs or PAMPs), conserved molecules present across microbial species, which elicit a series of defense responses ultimately resulting in plant immunity referred to as PAMP-triggered immunity (PTI). The restriction of microbial entry by stomatal closure, preinvasive or stomatal immunity, is one of the PTI responses that can be detected within minutes (Cao et al. 2011; Melotto et al. 2006). Chemically diverse MAMPs, such as flg22 (a conserved peptide of the bacterial flagellum), elf18 (a peptide comprising of the first18 amino acids of the bacterial elongation factor Tu), bacterial lipopolysaccharides (LPS), chitin (a component of the fungal cell wall), yeast elicitor, and oligogalacturonic acid (a degradation product of the plant cell wall) are all capable of inducing stomatal closure, and for flg22, it was further demonstrated that this limits bacterial colonization and disease breakout (Casabuono et al. 2011; Lee et al. 1999; Keinath et al. 2010; Klüsener et al. 2002; Melotto et al. 2006; Zeng and He 2010; Zipfel et al. 2004).

Microbe-induced stomatal closure depends on the perception of MAMPs by pattern recognition receptors (PRR) (Fig. 1). Global transcript analyses of guard cells indicate expression of the cognate PRR for detecting flg22, FLAGELLIN SENSING 2 (FLS2), and chitin, CHITIN ELICITOR RECEPTOR KINASE 
1 (Liu et al. 2009; Mersmann et al. 2010; Yang et al. 2008). Mutant $f l s 2$ plants are impaired in stomatal closure in response to flg22 and show increased susceptibility to $P$. syringae pv. tomato DC3000 when sprayed onto the leaf surface but not when infiltrated into leaves (Chinchilla et al. 2006; Gómez-Gómez and Boller 2000; Zeng and He 2010; Zipfel et al. 2004). Interestingly, MAMP-induced stomatal closure is not restricted to MAMP perception in leaves. Root inoculation with the rhizobacterium strain Bacillus subtilis FB17 not only reduces the average stomatal aperture but, also, decreases the percentage of open stomata in an FLS2-dependent manner (Kumar et al. 2012). Likewise, stomatal closure was observed when flg 22 and LPS were applied to roots. As a result, B. subtilis FB17-treated plants were more resistant to $P$. syringae pv. tomato DC3000 infection. These findings suggest that MAMP recognition in roots elicits a systemic signal provoking stomatal closure or that the MAMPs themselves could travel between tissues. As stomata respond in a cell-autonomous manner, not all stomata of a leaf close under MAMP stimulus (Melotto et al. 2006). It is, therefore, possible that the presence of a few nonresponsive stomata might be sufficient for highly virulent bacteria to enter the leaf and cause disease while, for less-virulent bacteria, more open stomata might be required for successful infection (Speth et al. 2009).

\section{Reactive oxygen species (ROS), $\mathrm{Ca}^{2+}$, and nitric oxide (NO) regulate stomatal apertures.}

ROS, NO, and cytosolic calcium elevations $\left(\left[\mathrm{Ca}^{2+}\right]_{\text {cyt }}\right)$ function in both MAMP- and ABA-induced stomatal closure. Production of $\mathrm{H}_{2} \mathrm{O}_{2}$, a major ROS, in response to ABA and different MAMPs is achieved only in part through overlapping components. $\mathrm{ABA}$ and flg22 trigger $\mathrm{H}_{2} \mathrm{O}_{2}$ production via the activation of plasma membrane-resident NADPH oxidases (Kwak et al. 2003; Mersmann et al. 2010). ABA-induced stomatal closure is largely impaired in mutant plants of the NADPH oxidase RESPIRATORY BURST OXIDASE HOMOLOGUE F (RBOHF) and is fully abolished in $r b o h D$ rbohF double mutants (Kwak et al. 2003). ROS production in response to MAMPs on the other hand, relies on RBOHD as the primary NADPH oxidase, and flg22- and elf18-dependent stomatal closure is abolished in the rbohD mutant (Macho et al. 2012; Mersmann et al. 2010). In addition, ASPARTATE OXIDASE, the enzyme catalyzing the first step in nicotinamide adenine dinucleotide (NAD) biosynthesis, is required for elf18- and flg22-elicited ROS burst and RBOHD-dependent stomatal closure without impacting the ABA-induced RBOHF-mediated ROS burst or ABA-induced stomatal closure (Macho et al. 2012). Chitin, yeast elicitor, and salicylic acid (SA) trigger ROS production independently of NADPH oxidases via activation of cell-wall peroxidases (Khokon et al. 2010a and b; Manthe et al. 1992). Though both biotic and abiotic stress-induced stomatal closures depend on ROS, these findings highlight different mechanisms of ROS production between ABA and individual MAMPs.

NO functions as a secondary messenger in ABA-dependent stomatal closure downstream of ROS production (Garcia-Mata and Lamattina 2007; Khokon et al. 2010a ; Neill et al. 2002; Saito et al. 2009). The MAMPs flg22, LPS, chitin, and yeast elicitor were shown to also induce guard cell-localized NO production (Khokon et al. 2010a; Ma et al. 2008; Melotto et al. 2006; Neill et al. 2002; Srivastava et al. 2009). The pathway of NO synthesis in plants as well as the role of NO in stomatal closure, however, is still under debate (Bellin et al. 2012; Yu et al. 2012). Because NO can covalently attach to cysteines to form $S$-nitrosothiol, a redox-based post-translational modification that can act as a molecular switch (Yu et al. 2012) and RBOHD is inactivated by $S$-nitrosylation (Bellin et al. 2012; Yun et al. 2011), this might represent a negative feedback loop during stomatal closure.

Perhaps the most important secondary messenger in MAMPand ABA-dependent stomatal closure is calcium. In a ROSdependent manner, ABA induces activation of a yet-unidentified plasma membrane hyperpolarization-activated $\left(\mathrm{I}_{\mathrm{Ca}}\right)$ channel, thereby eliciting $\mathrm{Ca}^{2+}$ elevations. Inhibition of $\mathrm{Ca}^{2+}$ elevations using the $\mathrm{Ca}^{2+}$ chelator BAPTA reduced ABA-triggered stomatal closure by $70 \%$ (Siegel et al. 2009). MAMPs, including LPS, chitin, and yeast elicitor, likewise provoke $\mathrm{I}_{\mathrm{Ca}}$ currents, and application of $\mathrm{Ca}^{2+}$ chelators as well as inhibitors of ROS generation prevented the chitin-induced stomatal closure in

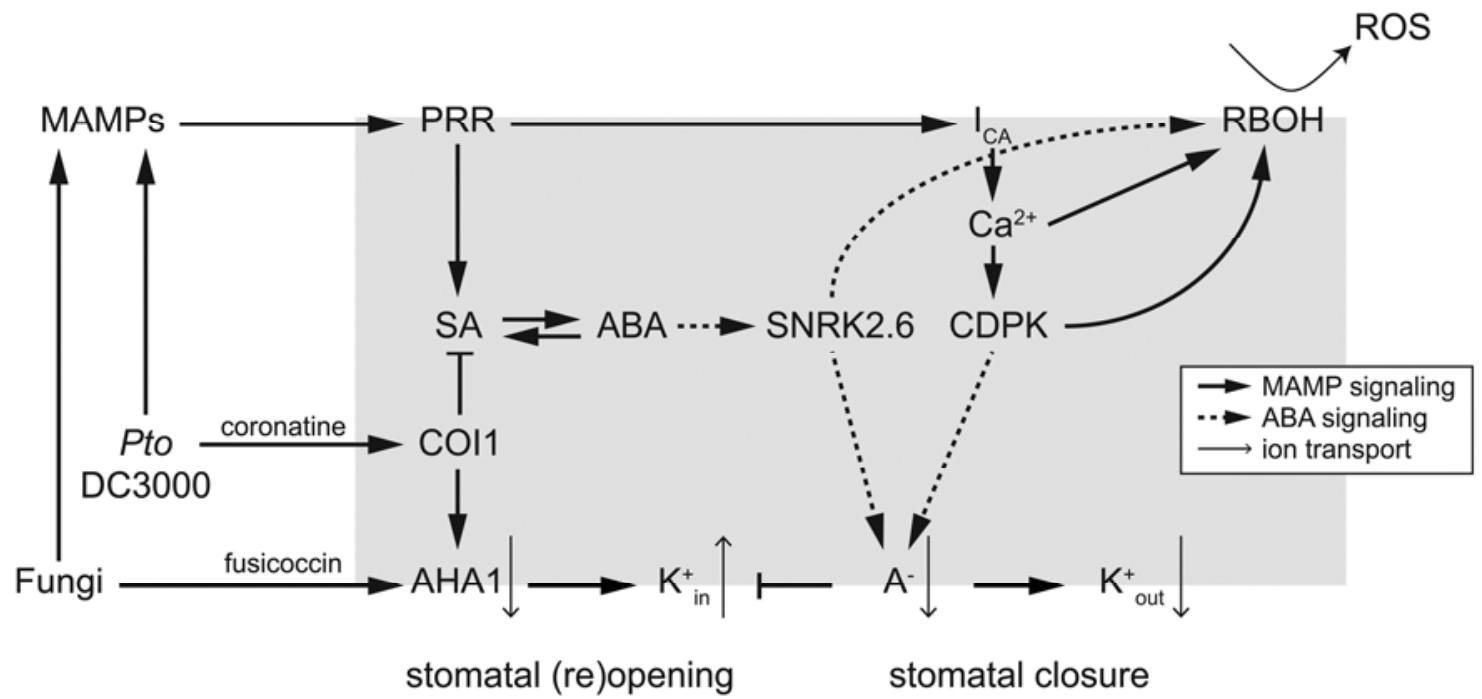

Fig. 1. Guard cell signaling in response to pathogen attack. Perception of microbe- associated molecular patterns (MAMPs) by pattern recognition receptors (PRR) triggers calcium channel $\left(\mathrm{I}_{\mathrm{CA}}\right)$ activation, increase of $\mathrm{Ca}^{2+}$ and in turn activates calcium-dependent protein kinases $(\mathrm{CDPK})$. CDPK and Ca ${ }^{2+}$ binding subsequently activate NADPH oxidases (respiratory burst homologues, RBOHs) and induce reactive oxygen species (ROS) production. CDPK also activate anion channels, as was shown in ABA-induced stomatal closure. This facilitates $\mathrm{K}^{+}$efflux through the function of outward rectifying channels $\left(\mathrm{K}^{+}{ }_{\text {out }}\right)$ and promotes decrease in guard cell turgor leading to stomatal closure. Microbe-induced stomatal closure involves ABA and SA as well as the Snf1-related pro-

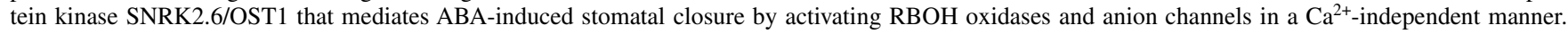
The pathogen effectors coronatine and fusicoccin activate the plasma membrane $\mathrm{H}^{+}$-ATPase AHA1/OST2, which in turn activates an inward rectifying $\mathrm{K}^{+}$ channel $\left(\mathrm{K}^{+}{ }_{\text {in }}\right)$ and promotes stomatal reopening. Coronatine also impairs SA production via CORONATINE INSENSITIVE 1 (COI1). 
Pisum sativum (Ali et al. 2007; Gan et al. 2012; Garcia-Mata and Lamattina 2007; Srivastava et al. 2009; Zeidler et al. 2004). In mesophyll cells, both, flg22 and elf18 trigger $\mathrm{Ca}^{2+}$ elevations that are independent of a prior ROS burst (Jeworutzki et al. 2010). This was, however, not tested in guard cells. Flg22triggered membrane depolarization is inhibited by the calcium channel blocker $\mathrm{La}^{3+}$, placing $\mathrm{Ca}^{2+}$ elevations upstream of ion channel regulation (Jeworutzki et al. 2010).

\section{Stomatal closure and opening requires channels and transporters.}

In response to MAMPs and ABA, the turgor of guard cells is reduced by efflux of anions and potassium ions, promoting the closure of stomata (Hedrich 2012). ABA activates two types of anion channels via phosphorylation, the slow-activating sustained (S-type) and the rapid transient (R-type) anion channels (Hedrich et al. 1990; Keller et al. 1989; Linder and Raschke 1992; Schroeder and Hagiwara 1989; Schroeder and Keller 1992), and the S-type anion channels SLAC1 and SLAH3 were reported to be regulated by ABA-induced guard cell signaling in Arabidopsis thaliana (Geiger et al. 2011; Negi et al. 2008; Vahisalu et al. 2008). Though similar in function, SLAH3 is strictly activated in a $\mathrm{Ca}^{2+}$-dependent manner while SLAC1 can also be activated independently of $\mathrm{Ca}^{2+}$ elevations (discussed below). For mediating stomatal closure, anion efflux causes membrane depolarization, which, in turn, drives potassium ions across the plasma membrane of the guard cells through outward-rectifying potassium channels (Ache et al. 2000; Hosy et al. 2003; Schroeder and Hagiwara 1989; Schroeder et al. 1984), water passively follows the flow of solutes and, eventually, the stomata close.

Like ABA, MAMP perception triggers membrane depolarization and increases the extracellular pH (Felix et al. 1993, 1999; Felle et al. 2004; Jeworutzki et al. 2010; Kuchitsu et al. 1997; Pelissier et al. 1986). In mesophyll cells, flg22- and elf18triggered membrane depolarization is achieved by activation of a nitrate and chloride permeable channel in a $\mathrm{Ca}^{2+}$-dependent manner (Garcia-Brugger et al. 2006; Jeworutzki et al. 2010). S-type anion channels are activated in guard cells in response to Blumeria graminis infection as well as chitin treatment, (Geiger et al. 2009, 2010; Koers et al. 2011), but neither the respective channels for the response to fungal chitin nor to the bacterial MAMPs flg22 and elf18 have been identified so far, which is an important question for future research (discussed below).

In addition to channels, ion fluxes across the plasma membrane are regulated by transporters including ATPases, some of which are differentially phosphorylated in response to MAMPs (Benschop et al. 2007). Plants expressing constitutive active variants of the Arabidopsis $\mathrm{H}^{+}$-ATPase 1 (AHA1/OST2) are impaired in stomatal closure induced by ABA or MAMPs (Merlot et al. 2007; Liu et al. 2009). AHA1 and its close homologue AHA2 are positively regulated by RPM1 INTERACTING PROTEIN 4 (RIN4), which is an important component of effector-triggered immunity and negatively regulates late PTI responses (Kim et al. 2005; Mackey et al. 2002). Mutant rin4 plants show decreased ATPase activity affecting the reopening of stomata in response to $P$. syringae pv. tomato DC3000 (Liu et al. 2009). RIN4 is a prerequisite for stomatal reopening by the bacterial effector coronatine (discussed below). In a similar manner, the fungus Fusicoccum amygdale produces the toxin fusicoccin that causes the activation of plasma membrane $\mathrm{H}^{+}$ATPases and thereby rapidly induces stomatal reopening (Baunsgaard et al. 1998; Oecking et al. 1997). Thus, one mode of action of some pathogens to counteract MAMP-induced stomatal closure is the activation of plasma membrane $\mathrm{H}^{+}-$ ATPases, thereby triggering stomatal opening.
Kinase signaling pathways mediating stomatal closure.

The SNF1-RELATED KINASE 2.6 (SNRK2.6/OST1) is a key component of the signaling pathway regulating stomatal apertures (Mustilli et al. 2002; Yoshida et al. 2006). In a $\mathrm{Ca}^{2+}$ independent manner, SNRK2.6 directly activates the S-type anion channel SLAC1 through phosphorylation that, in turn, mediates the movement of stomata (Geiger et al. 2009). Likewise, SNRK2.6 phosphorylates the NADPH oxidase RBOHF in vitro, suggesting a direct activation and as a result, ABAinduced ROS production is disrupted in guard cells of open stomata 1 (ost1) mutants (Mustilli et al. 2002; Sirichandra et al. 2009). A phosphoproteomic analysis revealed that RBOHD is phosphorylated on multiple sites in response to flg22 that are homologous to the RBOHF phosphorylation sites by SNRK2.6 (Benschop et al. 2007). Phosphorylation of RBOHB in Solanum tuberosum occurs in a similar region compared with RBOHF and RBOHD from Arabidopsis but at different sites and is mediated by CALCIUM-DEPENDENT PROTEIN KINASES (CDPK) (Kobayashi et al. 2007). In Arabidopsis, four CDPK function in both ABA and MAMP signaling pathways (CPK4, CPK6, and CPK11) and, based on initial experiments monitoring the induction of flg22-responsive genes, this would also expand to CPK3 (Boudsocq et al. 2010; Mori et al. 2006; Zhu et al. 2007). Mutant cpk3, cpk6, and cpk3 cpk6 plants are impaired in the ROS-mediated $\mathrm{I}_{\mathrm{Ca}}$ channel activation upon ABA treatment (Mori et al. 2006). This defect can be rescued by exogenous application of $\mathrm{H}_{2} \mathrm{O}_{2}$, which positions CDPK signaling upstream of $\mathrm{H}_{2} \mathrm{O}_{2}$ generation (Mori et al. 2006). Likewise, the flg22-induced ROS burst is down-regulated in cpk5 cpk6 mutants and is further reduced in cpk5 cpk6 cpk11 cpk4 $4^{\text {VIGS }}$ quadruple mutants (Boudsocq et al. 2010), pointing at CDPK signaling required for MAMP-triggered ROS production upstream of stomatal closure. Taken together, these findings provide evidence that parallel kinase-dependent signaling pathways mediate ROS production in a $\mathrm{Ca}^{2+}$-dependent and $\mathrm{Ca}^{2+}$-independent manner (Hubbard et al., 2012): i) ABA activates RBOHF via phosphorylation by the $\mathrm{Ca}^{2+}$-independent kinase SNRK2.6. The resulting ROS burst activates the plasma membrane-localized $\mathrm{I}_{\mathrm{Ca}}$ channel, generating $\mathrm{Ca}^{2+}$ elevations. $\mathrm{Ca}^{2+}$ in turn binds to the EF hands of RBOHF, leading to further activation of this NADPH oxidase (Kimura et al. 2012; Ogasawara et al. 2008); and ii) the $\mathrm{Ca}^{2+}$ elevations trigger CDPK-mediated RBOHF phosphorylation that further activates ROS production.

In parallel, CDPK target anion channels for mediating stomatal closure. Arabidopsis CPK6, CPK21, CPK23, and the constitutive active CPK3delEF variant phosphorylate and activate SLAC1 in oocytes (Brandt et al. 2012; Geiger et al. 2010; Scherzer et al. 2012). However, these CDPK target SLAC1 in a differential manner. Whereas CPK6 and CPK23 activate SLAC1 at resting $\mathrm{Ca}^{2+}$ levels (80 to $100 \mu \mathrm{M}$ ), CPK3 and CPK21 require increased $\mathrm{Ca}^{2+}$ levels (Scherzer et al. 2012). As a result, guard-cell protoplasts from cpk6 and cpk23 single mutants show reduced S-type anion channel activity in response to elevated $\mathrm{Ca}^{2+}$ levels (Geiger et al. 2010; Mori et al. 2006). S-type anion channel activity upon ABA treatment was not affected in cpk6 single mutants but in cpk3 cpk6 double mutants, revealing redundancy of CDPK signaling pathways in the ABA response (Mori et al. 2006).

Mitogen-activated protein kinases (MAPK) also play key roles in MAMP- and ABA-induced signaling pathways mediating stomatal closure and have long been associated with PTI and drought stress responses (Liu et al. 2010). MPK9 and MPK12 positively regulate ABA signaling in both stomatal closure and inhibition of light-induced stomatal opening (Jammes et al. 2009). Because ROS production and $\mathrm{Ca}^{2+}$ oscillation are unaffected in $m p k 9$ mpk12 mutants, this supports a 
downstream role for MPK9 and MPK12 in the signaling pathways for stomatal movements. In addition, mpk 9 mpk $12 \mathrm{mu}-$ tants are impaired in stomatal closure triggered by chitin and yeast elicitor, the likely cause of the observed increased susceptibility to $P$. syringae pv. tomato DC3000 infection (Jammes et al. 2011; Salam et al. 2012a and b). The major MAPK activated by flg22 in Arabidopsis are MPK3 and MPK6, which function downstream of ROS production and are also highly responsive to drought stress (Asai et al. 2002; Kovtun et al. 2000; Liu et al. 2010; Tsugama et al. 2012). Though these findings point at partially overlapping MAMP- and ABA-activated MAPK signaling pathways, guard cell-specific $m p k 3$ antisense lines are affected in closing stomata when triggered with bacteria or LPS but not ABA (Gudesblat et al. 2009), which suggests a specific requirement for MPK3 in MAMP-induced stomatal closure.

In addition to SNRK-, CDPK- and MAPK-type kinases, the AUTHENTIC HISTIDINE KINASE 5 (AHK5) is involved in regulating stomatal closure in response to MAMPs and ABA. Mutant ahk5 plants display reduced stomatal closing upon treatments with $\mathrm{H}_{2} \mathrm{O}_{2}$, ethylene, darkness, NO, flg22, P. syringae pv. tomato DC3000, and Botrytis cinerea (Choi et al. 2010). Interestingly, $\mathrm{H}_{2} \mathrm{O}_{2}$ production was strongly affected in ahk5 mutants, in particular, in response to flg 22 and ethylene. AHK5 therefore seems to be involved in both $\mathrm{H}_{2} \mathrm{O}_{2}$ production and signaling downstream of NO, possibly via a positive feedback loop. To conclude, the signaling pathways regulating stomatal apertures during biotic and abiotic stresses engage a range of different kinases functioning at different levels of the signaling cascade and partially acting redundantly. This suggests a tight interplay within and between the signaling pathways induced by MAMPs and ABA.

\section{Hormone crosstalk involved in stomatal movements.}

The plant hormones ABA, jasmonic acid (JA), and SA all function in MAMP-triggered stomatal closure. In preinvasive stomatal immunity, ABA acts as a positive regulator of stomatal closure (Asselbergh et al. 2008; Cao et al. 2011). Melotto and coworkers (2006) presented results indicating that pathogen-triggered stomatal closure in Arabidopsis is impaired in the ABA biosynthesis mutant aba deficient 3 (aba3-1) (Melotto et al. 2006). Whether this reflects a requirement for MAMP-induced ABA synthesis during stomatal closure or basal ABA levels remains to be addressed. To fully understand the intersection between ABA signaling and pathogen-triggered stomatal movements, it is important to take the different stages of the infection cycle into consideration. At 3 to $4 \mathrm{~h}$ postinoculation, $P$. syringae pv. tomato DC3000-inoculated plants reopen their stomata and ABA-induced gene regulation and stomatal closure are also partially impaired (Kim et al. 2011; Melotto et al. 2006). At later time points, $P$. syringae pv. tomato DC3000 increases in planta ABA levels, renders Arabidopsis plants hypersensitive towards $\mathrm{ABA}$, and thereby suppresses defense responses, all of which involves the function of secreted effectors HopAM1 and HopAB2 (de Torres-Zabala et al. 2007; Goel et al. 2008). Taken together, this provides evidences that, through the action of effectors, pathogens adjust the plant's physiological state associated with their infection cycle, keeping stomata open at the beginning of the infection phase and closing stomata later on to reduce further water loss. However, this needs to be further substantiated by detailed time-course experiments of stomatal movements and infection cycles, and it will be interesting to learn whether ABA acts in a guard cell-autonomous manner, as recently shown for stomatal responses to low air humidity (Bauer et al. 2013).

JA triggers the closure of stomata in a $\mathrm{Ca}^{2+}-$, ROS-, and NOdependent manner and requires the activation of $\mathrm{K}^{+}$-and $\mathrm{S}$-type anion channels (Evans 2003; Munemasa et al. 2007; Suhita et al. 2003, 2004). ABA-mediated stomatal closure is decreased in the JA-insensitive mutants jasmonate resistance 1 and coronatine insensitive 1. Conversely, JA-induced stomatal closure is reduced in the ABA-insensitive protein phosphatase $2 \mathrm{C} \mathrm{mu}$ tant aba insensitive 2, in the ABA-hyposensitive mutant ost 1 and in cpk6 mutants (Munemasa et al. 2007, 2011; Suhita et al. 2004), while low JA concentrations prevent ABA-induced stomatal closure (Speth et al. 2009). This highlights a tight interplay between the different hormones engaged in regulating stomatal apertures and provides evidence for overlapping ABA and JA signaling pathways upstream of ROS production. Coronatine, a $P$. syringae pv. tomato DC3000-secreted effector, structurally mimics JA-isoleucine (Melotto et al. 2006; Mittal and Davis 1995), thereby binding to the JA receptor complex consisting of CORONATINE INSENSITIVE 1 (COI1), an Fbox protein, and its substrate JASMONATE ZIM DOMAIN (JAZ) proteins (Yan et al. 2009). Binding of coronatine triggers COI1-dependent degradation of JAZ proteins, causing the degradation of SA and inhibition of SA biosynthesis, which, in turn, triggers the reopening of stomata (Melotto et al. 2006; Zheng et al. 2012). This mechanism enables P. syringae pv. tomato DC3000 to overcome PTI at the level of stomatal closure and to invade leaf tissues (Melotto et al. 2006; Zheng et al. 2012). Using the coronatine-deficient bacterial strain $P$. syringae pv. tomato DC3118, aspartate oxidase and SNRK2.6 as well as the SA biosynthesis gene ENHANCED DISEASE SUSCEPTIBILITY 5 were revealed as components of MAMP-induced stomatal closure (Macho et al. 2012; Zeng et al. 2011).

SA-induced stomatal closure requires ROS generated by peroxidases, which is downstream of NO production and inactivation of $\mathrm{K}^{+}$in channels (Khokon et al. 2011; Lee 1998; Manthe et al. 1992; Mori et al. 2001). SA-deficient plants, either overexpressing the SA hydroxylase $n a h G$ or mutant for $S A$ induction deficient 2 (sid2) are impaired in MAMP- and bacteriainduced stomatal closure, highlighting the importance of this hormone in stomatal immunity (Melotto et al. 2006). Mutant sidl/sid2 and nahG plants close stomata in response to exogenous ABA, whereas exogenous SA does not induce stomatal closure in the ABA-biosynthesis mutant aba2-1 (Zeng and He 2010). These findings position SA upstream of ABA signaling for mediating stomatal closure (Zeng and He 2010).

\section{Summary.}

Plants actively close stomata in response to pathogens via the perception of MAMPs by PRR like FLS2. MAMP-triggered stomatal closure requires the activation of anion channels, membrane depolarization, and subsequent activation of potassium channels. Stomatal closure induced by MAMPs engages a range of kinase signaling pathways (SNRK, CDPK, MAPK, $\mathrm{AHK}$ ) and is tightly intersected with hormone signaling (ABA, JA, SA). Guard-cell signaling seems to branch between MAMP- and ABA-induced pathways at the point of SNRK2.6. Thereafter each pathway targets different members of the NADPH oxidases, CDPK, MAPK, and AHK. While we have gained some knowledge about individual aspects and the molecular components of stomatal responses to MAMPs and effectors, we lack a comprehensive view of the signaling pathways and the mechanisms by which microbes trigger stomatal closure and successful pathogens can antagonize this response. A number of questions need to be addressed. i) What are the molecular components of guard cell signaling induced by microbes? In particular, what are the ion channels mediating stomatal closure and opening upon biotic stress? Are they the same as in ABA-induced stomatal closure? How are they regulated? ii) What is the role of SNRK2.6 during MAMP-induced stomatal closure? In particular, is SNRK2.6 biochemically acti- 
vated in response to MAMPs and thereby regulating SLAC1 activity? Does SNRK2.6 not phosphorylate RBOHF when activated by MAMPs? iii) Do MAMP signaling pathways differ between guard cells and the whole plant scale? Future works addressing these questions and, specifically, the intersection between the signaling pathways of MAMP- and ABAtriggered stomatal closure will further our understanding about how plants integrate biotic and abiotic stresses.

\section{ACKNOWLEDGMENTS}

Research activities in M. Böhmer's laboratory are supported by a research grant from the Deutsche Forschungsgemeinschaft (BO3155/3-1). Research in S. Robatzek's laboratory is supported by the Gatsby Charitable Foundation and by a grant of the European Research Council (ERC).

\section{NOTE ADDED IN PROOF}

While this manuscript was under review, an article by Montillet and associates (2013) suggesting an abscisic acid-independent oxylipin pathway controlling MAMP-induced stomatal closure in Arabidopsis was published.

\section{LITERATURE CITED}

Ache, P., Becker, D., Ivashikina, N., Dietrich, P., Roelfsema, M. R., and Hedrich, R. 2000. GORK, a delayed outward rectifier expressed in guard cells of Arabidopsis thaliana, is a $\mathrm{K}(+)$-selective, $\mathrm{K}(+)$-sensing ion channel. FEBS (Fed. Eur. Biochem. Soc.) Lett. 486:93-98.

Ali, R., Ma, W., Lemtiri-Chlieh, F., Tsaltas, D., Leng, Q., von Bodman, S., and Berkowitz, G.A. 2007. Death don't have no mercy and neither does calcium: Arabidopsis CYCLIC NUCLEOTIDE GATED CHANNEL2 and innate immunity. Plant Cell 19:1081-1095.

Asai, T., Tena, G., Plotnikova, J., Willmann, M., Chiu, W.-L., GomezGomez, L., Boller, T., Ausubel, F., and Sheen, J. 2002. MAP kinase signalling cascade in Arabidopsis innate immunity. Nature 415:977-983.

Asselbergh, B., De Vleesschauwer, D., and Hofte, M. 2008. Global switches and fine-tuning-ABA modulates plant pathogen defense. Mol. Plant-Microbe Interact. 21:709-719.

Bauer, H., Ache, P., Lautner, S., Fromm, J., Hartung, W., Al-Rasheid, Khaled, A. S., Sonnewald, S., Sonnewald, U., Kneitz, S., Lachmann, N., Mendel, Ralf, R., Bittner, F., Hetherington, Alistair, M., and Hedrich, R. 2013. The stomatal response to reduced relative humidity requires guard cell-autonomous ABA synthesis. Curr. Biol. 23:53-57.

Baunsgaard, L., Fuglsang, A. T., Jahn, T., Korthout, H. A. A. J., de Boer, A. H., and Palmgren, M. G. 1998. Summary. Plant J. 13:661-671.

Bellin, D., Asai, S., Delledonne, M., and Yoshioka, H. 2012. Nitric oxide as a mediator for defense responses. Mol. Plant-Microbe Interact. 26:271-277.

Benschop, J. J., Mohammed, S., O'Flaherty, M., Heck, A. J. R., Slijper, M., and Menke, F. L. H. 2007. Quantitative phosphoproteomics of early elicitor signaling in Arabidopsis. Mol. Cell. Prot. 6:1198-1214.

Boudsocq, M., Willmann, M. R., McCormack, M., Lee, H., Shan, L., He, P., Bush, J., Cheng, S. H., and Sheen, J. 2010. Differential innate immune signalling via $\mathrm{Ca}^{2+}$ sensor protein kinases. Nature 464:418-422.

Brandt, B., Brodsky, D. E., Xue, S., Negi, J., Iba, K., Kangasjarvi, J., Ghassemian, M., Stephan, A. B., Hu, H., and Schroeder, J. I. 2012. Reconstitution of abscisic acid activation of SLAC1 anion channel by CPK6 and OST1 kinases and branched ABI1 PP2C phosphatase action. Proc. Natl. Acad. Sci. U.S.A. 109:10593-10598.

Cao, F. Y., Yoshioka, K., and Desveaux, D. 2011. The roles of ABA in plant-pathogen interactions. J. Plant Res. 124:489-499.

Casabuono, A., Petrocelli, S., Ottado, J., Orellano, E. G., and Couto, A. S. 2011. Structural analysis and involvement in plant innate immunity of Xanthomonas axonopodis pv. citri lipopolysaccharide. J. Biol. Chem. 286:25628-25643.

Chinchilla, D., Bauer, Z., Regenass, M., Boller, T., and Felix, G. 2006. The Arabidopsis receptor kinase FLS2 binds flg22 and determines the specificity of flagellin perception. Plant Cell 18:465-476.

Choi, J., Huh, S. U., Kojima, M., Sakakibara, H., Paek, K. H., and Hwang, I. 2010. The cytokinin-activated transcription factor ARR2 promotes plant immunity via TGA3/NPR1-dependent salicylic acid signaling in Arabidopsis. Dev. Cell 19:284-295.

de Torres-Zabala, M., Truman, W., Bennett, M. H., Lafforgue, G., Mansfield, J. W., Egea, P. R., Bogre, L., and Grant, M. 2007. Pseudomonas syringae pv. tomato hijacks the Arabidopsis abscisic acid signalling pathway to cause disease. EMBO (Eur. Mol. Biol. Organ.) J. 26:1434-1443.
Dickinson, S. 1949. Studies in the physiology of obligate parasitism: II. The behaviour of the germ-tubes of certain rusts in contact with various membranes. Ann. Bot. 13:219-236.

Espino, R. R. C., and Nesbitt, W. B. 1982. Infection and development of Plasmopara viticola (B. et C.) Berl. et de T. on resistant and susceptible gravepines (Vitis sp.). Philipp. J. Crop Science 7:114-116.

Evans, N. H. 2003. Modulation of guard cell plasma membrane potassium currents by methyl jasmonate. Plant Physiol. 131:8-11.

Felix, G., Regenass, M., and Boller, T. 1993. Specific perception of subnanomolar concentrations of chitin fragments by tomato cells-Induction of extracellular alkalinization, changes in protein-phosphorylation, and establishment of a refractory state. Plant J. 4:307-316.

Felix, G., Duran, J. D., Volko, S., and Boller, T. 1999. Plants have a sensitive perception system for the most conserved domain of bacterial flagellin. Plant J. 18:265-276.

Felle, H. H., Herrmann, A., Hanstein, S., Hückelhoven, R., and Kogel, K.-H. 2004. Apoplastic $\mathrm{pH}$ signaling in barley leaves attacked by the powdery mildew fungus Blumeria graminis f. sp hordei. Mol. Plant-Microbe Interact. 17:118-123.

Gan, Q., Jia, B., Liu, X., Zhang, Y. Z., and Liu, M. X. 2012. Studies on calcium release and $\mathrm{H}_{2} \mathrm{O}_{2}$ level produced by the elicitor induced plant cell by fluorescence probing. J. Fluoresc. 22:573-581.

Garcia-Brugger, A., Lamotte, O., Vandelle, E., Bourque, S., Lecourieux, D., Poinssot, B., Wendehenne, D., and Pugin, A. 2006. Early signaling events induced by elicitors of plant defenses. Mol. Plant-Microbe Interact. 19:711-724.

Garcia-Mata, C., and Lamattina, L. 2007. Abscisic acid (ABA) inhibits light-induced stomatal opening through calcium- and nitric oxide-mediated signaling pathways. Nitric Oxide 17:143-151.

Geiger, D., Scherzer, S., Mumm, P., Stange, A., Marten, I., Bauer, H., Ache, P., Matschi, S., Liese, A., Al-Rasheid, K.A., Romeis, T., and Hedrich, R. 2009. Activity of guard cell anion channel SLAC1 is controlled by drought-stress signaling kinase-phosphatase pair. Proc. Natl. Acad. Sci. U.S.A. 106:21425-21430.

Geiger, D., Scherzer, S., Mumm, P., Marten, I., Ache, P., Matschi, S., Liese, A., Wellmann, C., Al-Rasheid, K.A.S., Grill, E., Romeis, T., and Hedrich, R. 2010. Guard cell anion channel SLAC1 is regulated by CDPK protein kinases with distinct $\mathrm{Ca}^{2+}$ affinities. Proc. Natl. Acad. Sci. U.S.A. 107:8023-8028.

Geiger, D., Maierhofer, T., Al-Rasheid, K.A.S., Scherzer, S., Mumm, P. Liese, A., Ache, P., Wellmann, C., Marten, I., Grill, E., Romeis, T., and Hedrich, R. 2011. Stomatal closure by fast abscisic acid signaling is mediated by the guard cell anion channel SLAH3 and the receptor RCAR1. Sci. Signal. 4:ra32. Published online.

Goel, A. K., Lundberg, D., Torres, M. A., Matthews, R., AkimotoTomiyama, C., Farmer, L., Dangl, J. L., and Grant, S. R. 2008. The Pseudomonas syringae type III effector HopAM1 enhances virulence on water-stressed plants. Mol. Plant-Microbe Interact. 21:361-370.

Gómez-Gómez, L., and Boller, T. 2000. FLS2: An LRR receptor-like kinase involved in the perception of the bacterial elicitor flagellin in Arabidopsis. Mol Cell 5:1003-1011.

Gudesblat, G. E., Torres, P. S., and Vojnov, A. A. 2009. Xanthomonas campestris overcomes Arabidopsis stomatal innate immunity through a DSF cell-to-cell signal-regulated virulence factor. Plant Physiol. 149:10171027.

Hedrich, R. 2012. Ion channels in plants. Physiol. Rev. 92:1777-1811.

Hedrich, R., Busch, H., and Raschke, K. 1990. Ca ${ }^{2+}$ and nucleotide dependent regulation of voltage dependent anion channels in the plasma membrane of guard cells. EMBO (Eur. Mol. Biol. Organ.) J. 9:38893892.

Hosy, E., Vavasseur, A., Mouline, K., Dreyer, I., Garmard, F., Poree, F., Boucherz, J., Lebaudy, A., Bouchez, D., Very, A. A., Simoneau, T., Thibaud, J. B., and Sentenac, H. 2003. The Arabidiopsis outward K ${ }^{+}$ channel GORK is involved in regulation of stomatal movements and plant transpiration. Proc. Natl. Acad. Sci. U.S.A. 100:5549-5554.

Hubbard, K. E., Siegel, R. S., Valerio, G., Brandt, B., and Schroeder, J. I. 2012. Abscisic acid and $\mathrm{CO}_{2}$ signalling via calcium sensitivity priming in guard cells, new CDPK mutant phenotypes and a method for improved resolution of stomatal stimulus-response analyses. Ann. Bot. 109:5-17.

Hugouvieux, V., Barber, C. E., and Daniels, M. J. 1998. Entry of Xanthomonas campestris pv. campestris into hydathodes of Arabidopsis thaliana leaves: A system for studying early infection events in bacterial pathogenesis. Mol. Plant-Microbe Interact. 11:537-543.

Jammes, F., Song, C., Shin, D., Munemasa, S., Takeda, K., Gu, D., Cho, D. Lee, S., Giordo, R., Sritubtim, S., Leonhardt, N., Ellis, B. E., Murata, Y., and Kwak, J. M. 2009. MAP kinases MPK9 and MPK12 are preferentially expressed in guard cells and positively regulate ROS-mediated ABA signaling. Proc. Natl. Acad. Sci. U.S.A. 106:20520-20525.

Jammes, F., Yang, X., Xiao, S., and Kwak, J. M. 2011. Two Arabidopsis 
guard cell-preferential MAPK genes, MPK9 and MPK12, function in biotic stress response. Plant Signal Behav. 6:1875-1877.

Jeworutzki, E., Roelfsema, M. R., Anschütz, U., Krol, E., Elzenga, J. T., Felix, G., Boller, T., Hedrich, R., and Becker, D. 2010. Early signaling through the Arabidopsis pattern recognition receptors FLS2 and EFR involves Ca-associated opening of plasma membrane anion channels. Plant J. 62:367-378

Keinath, N. F., Kierszniowska, S., Lorek, J., Bourdais, G., Kessler, S. A., Shimosato-Asano, H., Grossniklaus, U., Schulze, W. X., Robatzek, S., and Panstruga, R. 2010. PAMP (pathogen-associated molecular pattern)-induced changes in plasma membrane compartmentalization reveal novel components of plant immunity. J. Biol. Chem. 285:3914039149.

Keller, B. U., Hedrich, R., and Raschke, K. 1989. Voltage-dependent anion channels in the plasma membrane of guard cells. Nature 341:450-453.

Khokon, M. A., Hossain, M. A., Munemasa, S., Uraji, M., Nakamura, Y., Mori, I. C., and Murata, Y. 2010a. Yeast elicitor-induced stomatal closure and peroxidase-mediated ROS production in Arabidopsis. Plant Cell Physiol. 51:1915-1921.

Khokon, M. A., Uraji, M., Munemasa, S., Okuma, E., Nakamura, Y., Mori, I. C., and Murata, Y. 2010b. Chitosan-induced stomatal closure accompanied by peroxidase-mediated reactive oxygen species production in Arabidopsis. Biosci. Biotechnol. Biochem. 74:2313-2315.

Khokon, A. R., Okuma, E., Hossain, M. A., Munemasa, S., Uraji, M., Nakamura, Y., Mori, I. C., and Murata, Y. 2011. Involvement of extracellular oxidative burst in salicylic acid-induced stomatal closure in Arabidopsis. Plant Cell Environ. 34:434-443.

Kiefer, B., Riemann, M., Büche, C., Kassemeyer, H.-H., and Nick, P. 2002. The host guides morphogenesis and stomatal targeting in the grapevine pathogen Plasmopara viticola. Planta 215:387-393.

Kim, M. G., da Cunha, L., McFall, A. J., Belkhadir, Y., DebRoy, S., Dangl, J. L., and Mackey, D. 2005. Two Pseudomonas syringae type III effectors inhibit RIN4-regulated basal defense in Arabidopsis. Cell 121:749759 .

Kim, T.-H., Hauser, F., Ha, T., Xue, S., Böhmer, M., Nishimura, N., Munemasa, S., Hubbard, K., Peine, N., Lee, B.-h., Lee, S., Robert, N., Parker, J. E., and Schroeder, J.I. 2011. Chemical Genetics reveals negative regulation of abscisic acid signaling by a plant immune response pathway. Curr. Biol. 21:990-997.

Kimura, S., Kaya, H., Kawarazaki, T., Hiraoka, G., Senzaki, E., Michikawa, M., and Kuchitsu, K. 2012. Protein phosphorylation is a prerequisite for the $\mathrm{Ca}^{2+}$-dependent activation of Arabidopsis NADPH oxidases and may function as a trigger for the positive feedback regulation of $\mathrm{Ca}^{2+}$ and reactive oxygen species. Biochim Biophys Acta 1823:398-405.

Klüsener, B., Young, J. J., Murata, Y., Allen, G. J., Mori, I. C., Hugouvieux, V., and Schroeder, J. I. 2002. Convergence of calcium signaling pathways of pathogenic elicitors and abscisic acid in Arabidopsis guard cells. Plant Physiol. 130:2152-2163.

Kobayashi, M., Ohura, I., Kawakita, K., Yokota, N., Fujiwara, M., Shimamoto, K., Doke, N., and Yoshioka, H. 2007. Calcium-Dependent Protein Kinases Regulate the Production of Reactive Oxygen Species by Potato NADPH Oxidase. Plant Cell 19:1065-1080.

Koers, S., Guzel-Deger, A., Marten, I., and Roelfsema, M. R. G. 2011 Barley mildew and its elicitor chitosan promote closed stomata by stimulating guard-cell S-type anion channels. Plant J. 68:670-680.

Kovtun, Y., Chiu, W. L., Tena, G., and Sheen, J. 2000. Functional analysis of oxidative stress-activated mitogen-activated protein kinase cascade in plants. Proc. Natl. Acad. Sci. U.S.A. 97:2940-2945.

Kroupitski, Y., Golberg, D., Belausov, E., Pinto, R., Swartzberg, D., Granot, D., and Sela, S. 2009. Internalization of Salmonella enterica in leaves is induced by light and involves chemotaxis and penetration through open stomata. Appl. Environ. Microbiol. 75:6076-6086.

Kroupitski, Y., Pinto, R., Belausov, E., and Sela, S. 2011. Distribution of Salmonella typhimurium in romaine lettuce leaves. Food Microbiol 28:990-997.

Kuchitsu, K., Yazaki, Y., Sakano, K., and Shibuya, N. 1997. Transient cytoplasmic $\mathrm{pH}$ change and ion fluxes through the plasma membrane in suspension-cultured rice cells triggered by $\mathrm{N}$-acetylchitooligosaccharide elicitor. Plant Cell Physiol. 38:1012-1018.

Kumar, A. S., Lakshmanan, V., Caplan, J. L., Powell, D., Czymmek, K. J., Levia, D. F., and Bais, H. P. 2012. Rhizobacteria Bacillus subtilis restricts foliar pathogen entry through stomata. Plant J. 72:694-706.

Kwak, J. M., Mori, I. C., Pei, Z. M., Leonhardt, N., Torres, M. A., Dangl, J. L., Bloom, R. E., Bodde, S., Jones, J. D., and Schroeder, J. I. 2003. NADPH oxidase AtrbohD and AtrbohF genes function in ROS-dependent ABA signaling in Arabidopsis. EMBO (Eur. Mol. Biol. Organ.) J. 22:2623-2633.

Lee, J.-S. 1998. The mechanism of stomatal closing by salicylic acid in Commelina communis L. J. Plant Biol. 41:97-102.
Lee, S., Choi, H., Suh, S., Doo, I. S., Oh, K. Y., Choi, E. J., Schroeder Taylor, A. T., Low, P. S., and Lee, Y. 1999. Oligogalacturonic acid and chitosan reduce stomatal aperture by inducing the evolution of reactive oxygen species from guard cells of tomato and Commelina communis. Plant Physiol. 121:147-152.

Linder, B., and Raschke, K. 1992. A slow anion channel in guard cells, activation at large hyperpolarization, may be principal for stomatal closing. FEBS (Fed. Eur. Biochem. Soc.) Lett. 131:27-30.

Liu, J., Elmore, J. M., Fuglsang, A. T., Palmgren, M. G., Staskawicz, B. J., and Coaker, G. 2009. RIN4 functions with plasma membrane $\mathrm{H}^{+}$ ATPases to regulate stomatal apertures during pathogen attack. PLoS Biol 7:e1000139. Pjublished online.

Liu, Y. K., Liu, Y. B., Zhang, M. Y., and Li, D. Q. 2010. Stomatal development and movement: The roles of MAPK signaling. Plant Signal Behav. 5:1176-1180.

Ma, W., Smigel, A., Tsai, Y. C., Braam, J., and Berkowitz, G. A. 2008. Innate immunity signaling: Cytosolic $\mathrm{Ca}^{2+}$ elevation is linked to downstream nitric oxide generation through the action of calmodulin or a calmodulin-like protein. Plant Physiol. 148:818-828.

Macho, A. P., Boutrot, F., Rathjen, J. P., and Zipfel, C. 2012. ASPARTATE OXIDASE plays an important role in Arabidopsis stomatal immunity. Plant Physiol. 159:1845-1856.

Mackey, D., Holt, B. F., Wiig, A., and Dangl, J. L. 2002. RIN4 interacts with Pseudomonas syringae type III effector molecules and is required for RPM1-mediated resistance in Arabidopsis. Cell 108:743-754.

Maheshwari, R., Hildebrandt, A. C., and Allen, P. J. 1967. The cytology of infection structure development in urediospore germ tubes of typica (Pers.) Wint. Can. J. Bot. 45:447-450.

Manthe, B., Schulz, M., and Schnabl, H. 1992. Effects of salicylic acid on growth and stomatal movements of Vicia faba L.: Evidence for salicylic acid metabolization. J. Chem. Ecol. 18:1525-1539.

Melotto, M., Underwood, W., Koczan, J., Nomura, K., and He, S. Y. 2006. Plant stomata function in innate immunity against bacterial invasion. Cell 126:969-980.

Mendgen, K., Wirsel, S. G., Jux, A., Hoffmann, J., and Boland, W. 2006. Volatiles modulate the development of plant pathogenic rust fungi. Planta 224:1353-1361.

Merlot, S., Leonhardt, N., Fenzi, F., Valon, C., Costa, M., Piette, L., Vavasseur, A., Genty, B., Boivin, K., Muller, A., Giraudat, J., and Leung, J. 2007. Constitutive activation of a plasma membrane $\mathrm{H}(+)$ ATPase prevents abscisic acid-mediated stomatal closure. EMBO (Eur. Mol. Biol. Organ.) J. 26:3216-3226.

Mersmann, S., Bourdais, G., Rietz, S., and Robatzek, S. 2010. Ethylene signaling regulates accumulation of the FLS2 receptor and is required for the oxidative burst contributing to plant immunity. Plant Physiol. 154:391-400

Mittal, S., and Davis, K. R. 1995. Role of the phytotoxin coronatine in the infection of Arabidopsis thaliana by Pseudomonas syringae pv. tomato. Mol. Plant-Microbe Interact. 8:165-171.

Moldenhauer, J., Moerschbacher, B.M., and Van der Westhuizen, A. J. 2006. Histological investigation of stripe rust (Puccinia striiformis f.sp tritici) development in resistant and susceptible wheat cultivars. Plant Pathol. 55:469-474.

Montillet, J.-L., Leonhardt, N., Mondy, S., Tranchimand, S., Rumeau, D., Boudsocq, M., Garcia, A. V., Douki, T., Bigeard, J., Laurière, C., Chevalier, A., Castresana, C., and Hirt, H. 2013. An abscisic acidindependent oxylipin pathway controls stomatal closure and immune defense in Arabidopsis. PLoS Biol 11:e1001513. Published online.

Mori, I. C., Pinontoan, R., Kawano, T., and Muto, S. 2001. Involvement of superoxide generation in salicylic acid-induced stomatal closure in vicia faba. Plant Cell Physiol. 42:1383-1388.

Mori, I. C., Murata, Y., Yang, Y., Munemasa, S., Wang, Y.-F., Andreoli, S. Tiriac, H., Alonso, J. M., Harper, J. F., Ecker, J. R., Kwak, J. M., and Schroeder, J. I. 2006. CDPKs CPK6 and CPK3 function in ABA regulation of guard cell S-type anion- and $\mathrm{Ca}^{2+}$ permeable channels and stomatal closure. PLoS Biology 4:e327. Published online.

Munemasa, S., Oda, K., Watanabe-Sugimoto, M., Nakamura, Y., Shimoishi, Y., and Murata, Y. 2007. The coronatine-insensitive 1 mutation reveals the hormonal signaling interaction between abscisic acid and methyl jasmonate in Arabidopsis guard cells. Specific impairment of ion channel activation and second messenger production. Plant Physiol. 143:1398-1407.

Munemasa, S., Hossain, M. A., Nakamura, Y., Mori, I. C., and Murata, Y. 2011. The Arabidopsis calcium-dependent protein kinase, CPK6, functions as a positive regulator of methyl jasmonate signaling in guard cells. Plant Physiol. 155:553-561.

Mustilli, A. C., Merlot, S., Vavasseur, A., Fenzi, F., and Giraudat, J. 2002. Arabidopsis OST1 protein kinase mediates the regulation of stomatal aperture by abscisic acid and acts upstream of reactive oxygen species production. Plant Cell 14:3089-3099. 
Negi, J., Matsuda, O., Nagasawa, T., Oba, Y., Takahashi, H., KawaiYamada, M., Uchimiya, H., Hashimoto, M., and Iba, K. 2008. $\mathrm{CO}_{2}$ regulator SLAC1 and its homologues are essential for anion homeostasis in plant cells. Nature 452:483-486.

Neill, S. J., Desikan, R., Clarke, A., and Hancock, J. T. 2002. Nitric oxide is a novel component of abscisic acid signaling in stomatal guard cells. Plant Physiol. 128:13-16.

Oecking, C., Piotrowski, M., Hagemeier, J., and Hagemann, K. 1997. Topology and target interaction of the fusicoccin-binding 14-3-3 homologs of Commelina communis. Plant J. 12:441-453.

Ogasawara, Y., Kaya, H., Hiraoka, G., Yumoto, F., Kimura, S., Kadota, Y. Hishinuma, H., Senzaki, E., Yamagoe, S., Nagata, K., Nara, M., Suzuki, K., Tanokura, M., and Kuchitsu, K. 2008. Synergistic activation of the Arabidopsis NADPH oxidase AtrbohD by $\mathrm{Ca}^{2+}$ and phosphorylation. J. Biol. Chem. 283:14:8885-8892.

Pelissier, B., Thibaud, J.B., Grignon, C., and Esquerretugaye, M. T. 1986. Cell-Surfaces in Plant-Microorganism Interactions. VII. Elicitor preparations from two fungal pathogens depolarize plant membranes. Plant Sci. 46:103-109.

Ramos, L. J., and Volin., R. B. 1987. Role of stomatal opening and frequency on infection of Lycopersicon spp. by Xanthomonas campestris pv. vesicatoria. Phytopathology 77:1311-1317.

Saito, N., Nakamura, Y., Mori, I. C., and Murata, Y. 2009. Nitric oxide functions in both methyl jasmonate signaling and abscisic acid signaling in Arabidopsis guard cells. Plant Signal Behav. 4:119-120.

Salam, M. A., Jammes, F., Hossain, M. A., Ye, W., Nakamura, Y., Mori, I. C., Kwak, J. M., and Murata, Y. 2012a. Two guard cell-preferential MAPKs, MPK9 and MPK12, regulate YEL signalling in Arabidopsis guard cells. Plant Biol. (Stuttg.) 10.1111/j.1438-8677.2012.00671.x. Published online.

Salam, M. A., Jammes, F., Hossain, M. A., Ye, W., Nakamura, Y., Mori, I. C., Kwak, J. M., and Murata, Y. 2012b. MAP Kinases, MPK9 and MPK12, regulate chitosan-induced stomatal closure. Biosci. Biotechnol. Biochem. 76:1785-1787.

Scherzer, S., Maierhofer, T., Al-Rasheid, K. A. S., Geiger, D., and Hedrich, R. 2012. Multiple calcium-dependent kinases modulate ABAactivated guard cell anion channels. Mol. Plant. 5:1409-1412.

Schroeder, J. I., and Hagiwara, S. 1989. Cytosolic calcium regulates ion channels in the plasma membrane of Vicia faba guard cells. Nature 338:427-430.

Schroeder, J. I., and Keller, B. U. 1992. Two types of anion channel currents in guard cells with distinct voltage regulation. Proc. Natl. Acad. Sci. U.S.A. 89:5025-5029.

Schroeder, J. I., Hedrich, R., and Fernandez, J. M. 1984. Potassium-selective single channels in guard cell protoplasts of Vicia faba. Nature 312:361-362

Siegel, R. S., Xue, S., Murata, Y., Yang, Y., Nishimura, N., Wang, A., and Schroeder, J. I. 2009. Calcium elevation-dependent and attenuated resting calcium-dependent abscisic acid induction of stomatal closure and abscisic acid-induced enhancement of calcium sensitivities of S-type anion and inward-rectifying $\mathrm{K}$ channels in Arabidopsis guard cells. Plant J. 59:207-220.

Sirichandra, C., Gu, D., Hu, H. C., Davanture, M., Lee, S., Djaoui, M. Valot, B., Zivy, M., Leung, J., Merlot, S., and Kwak, J. M. 2009. Phosphorylation of the Arabidopsis AtrbohF NADPH oxidase by OST1 protein kinase. FEBS (Fed. Eur. Biochem. Soc.) Lett. 583:2982-2986.

Speth, E. B., Melotto, M., Zhang, W., Assmann, S. M., and He, S. Y. 2009 Crosstalk in Pathogen and hormonal regulation of guard cell signaling. Pages 96-112 in: Signal Crosstalk in Plant Stress Responses, WileyBlackwell, Hoboken, NJ, U.S.A.

Srivastava, N., Gonugunta, V. K., Puli, M. R., and Raghavendra, A. S. 2009. Nitric oxide production occurs downstream of reactive oxygen species in guard cells during stomatal closure induced by chitosan in abaxial epidermis of Pisum sativum. Planta 229:757-765.

Staples, R. C. 2000. Research on the rust fungi during the twentieth century. Annu. Rev. Phytopathol. 38:49-69.

Suhita, D., Kolla, V. A., Vavasseur, A., and Raghavendra, A. S. 2003. Different signaling pathways involved during the suppression of stomatal opening by methyl jasmonate or abscisic acid. Plant Sci. 164:481-488

Suhita, D., Raghavendra, A. S., Kwak, J. M., and Vavasseur, A. 2004. Cytoplasmic alkalization precedes reactive oxygen species production during methyl jasmonate- and abscisic acid-induced stomatal closure. Plant Physiol. 134:1536-1545.

Tsugama, D., Liu, S., and Takano, T. 2012. Drought-induced activation and rehydration-induced inactivation of MPK6 in Arabidopsis. Biochem. Biophys. Res. Commun. 426:626-629.

Vahisalu, T., Kollist, H., Wang, Y. F., Nishimura, N., Chan, W. Y., Valerio, G., Lamminmaki, A., Brosche, M., Moldau, H., Desikan, R., Schroeder, J. I., and Kangasjarvi, J. 2008. SLAC1 is required for plant guard cell S-type anion channel function in stomatal signalling. Nature 452:487-491.

Yan, J. B., Zhang, C., Gu, M., Bai, Z. Y., Zhang, W. G., Qi, T. C., Cheng, Z. W., Peng, W., Luo, H. B., Nan, F. J., Wang, Z., and Xie, D. X. 2009. The Arabidopsis CORONATINE INSENSITIVE1 protein is a jasmonate receptor. Plant Cell 21:2220-2236.

Yang, Y., Costa, A., Leonhardt, N., Siegel, R. S., and Schroeder, J. I. 2008. Isolation of a strong Arabidopsis guard cell promoter and its potential as a research tool. Plant Methods 4:6.

Yoshida, R., Umezawa, T., Mizoguchi, T., Takahashi, S., Takahashi, F., and Shinozaki, K. 2006. The regulatory domain of SRK2E/OST1/SnRK2.6 interacts with $\mathrm{ABI} 1$ and integrates abscisic acid (ABA) and osmotic stress signals controlling stomatal closure in Arabidopsis. J. Biol. Chem. 281:5310-5318.

Yu, M., Yun, B.-W., Spoel, S. H., and Loake, G. J. 2012. A sleigh ride through the SNO: Regulation of plant immune function by protein S nitrosylation. Curr. Opinion Plant Biol. 15:424-430.

Yun, B. W., Feechan, A., Yin, M. H., Saidi, N. B. B., Le Bihan, T., Yu, M., Moore, J. W., Kang, J. G., Kwon, E., Spoel, S. H., Pallas, J. A., and Loake, G. J. 2011. S-nitrosylation of NADPH oxidase regulates cell death in plant immunity. Nature 478:264-U161.

Zeidler, D., Zähringer, U., Gerber, I., Dubery, I., Hartung, T., Bors, W. Hutzler, P., and Durner, J. 2004. Innate immunity in Arabidopsis thaliana: Lipopolysaccharides activate nitric oxide synthase (NOS) and induce defense genes. Proc. Natl. Acad. Sci. U.S.A. 101:15811-15816.

Zeng, W., and He, S. Y. 2010. A prominent role of the flagellin receptor FLAGELLIN-SENSING2 in mediating stomatal response to Pseudomonas syringae pv. tomato DC3000 in Arabidopsis. Plant Physiol. 153:1188-1198.

Zeng, W. Q., Brutus, A., Kremer, J. M., Withers, J. C., Gao, X. L., Jones, A D., and He, S. Y. 2011. A genetic screen reveals Arabidopsis stomatal and/or apoplastic defenses against Pseudomonas syringae pv. tomato DC3000. PloS Pathog. 7:e1002291. doi:10.1371/journal.ppat.1002291. Published online.

Zheng, X. Y., Spivey, N. W., Zeng, W., Liu, P. P., Fu, Z. Q., Klessig, D. F., He, S. Y., and Dong, X. 2012. Coronatine promotes Pseudomonas syringae virulence in plants by activating a signaling cascade that inhibits salicylic acid accumulation. Cell Host Microbe 11:587-596.

Zhu, S. Y., Yu, X. C., Wang, X. J., Zhao, R., Li, Y., Fan, R. C., Shang, Y., Du, S. Y., Wang, X. F., Wu, F. Q., Xu, Y. H., Zhang, X. Y., and Zhang, D. P. 2007. Two calcium-dependent protein kinases, CPK4 and CPK11, regulate abscisic acid signal transduction in Arabidopsis. Plant Cell 19:3019-3036.

Zipfel, C., Robatzek, S., Navarro, L., Oakeley, E. J., Jones, J. D. G., Felix, G., and Boller, T. 2004. Bacterial disease resistance in Arabidopsis through flagellin perception. Nature 428:764-767. 